\title{
INTESTINAL OBSTRUCTION IN THE NEWBORN WITH SPECIAL REFERENCE TO TRANSIENT FUNCTIONAL ILEUS ASSOCIATED WITH RESPIRATORY DISTRESS SYNDROME
}

\author{
BY \\ PETER M. DUNN* \\ From the Maternity Hospital, Birmingham
}

(RECEIVED FOR PUBLICATION FEBRUARY 22, 1963)

Surgical advances over the last half century have steadily reduced the mortality from intestinal obstruction in the newborn. However, transient intestinal obstruction of functional rather than anatomical origin is not uncommon in the first few days of life. As surgery may be strongly contraindicated in this group, the differential diagnosis is extremely important. It is hoped that the following study of this problem made in a maternity hospital may indicate some of the clinical signs of value in the differential diagnosis.

\section{Clinical Material}

During 1960 and 1961, 4,754 babies were born at the Birmingham Maternity Hospital. Intestinal obstruction was diagnosed either at birth or during the first few days of life in 24 infants. In the former there was no diagnostic difficulty; in the latter, the diagnosis was based on the presence of at least two and usually all three of the following signs-abdominal distension, delayed passage of meconium and bile-stained vomiting. In 12 infants the intestinal obstruction was due to an anatomical abnormality. In nine (Cases 1-9) this was apparent at birth; in three (Cases 10-12) it became apparent during the first few days of life. Short case summaries are given below.

Case 1. Duodenal atresia; stillborn; maternal hydramnios present.

Case 2. Duodenal stenosis and multiple abnormalities; died on first day; no maternal hydramnios.

Case 3. Ileal atresia; stillborn following a destructive operation because of dystocia due to gross foetal abdominal distension. No maternal hydramnios.

Cases 4-9. Imperforate anus, six cases. One stillborn; two with other malformations died; three survived. No maternal hydramnios.

*Present address: Bristol Maternity Hospital, Bristol,
Case 10. Duodenal atresia; severe hydramnios and premature labour; white stools, thick dark green-brown vomit and epigastric distension on second day. Radiograph showed typical 'double-bubble' appearance. Surgical correction on third day. Survived.

Case 11. Ileal atresia; severe hydramnios; pale green stool, copious thick green-brown vomit and upper abdominal distension on second day. Radiograph showed gross distension of intestine as far as the ileum and no gas below this level (Fig. 1). Surgical correction on second day. Survived.

Case 12. Ileal stenosis due to very recent ulceration near the ileo-colic valve secondary to vascular insufficiency; no hydramnios; premature caesarian delivery because of toxaemia of pregnancy; abdominal distension and bile-stained vomiting from the third day; meconium passed daily; bowel sounds intermittent; radiograph (Fig. 2) showed 'general distension of the gut with air down to the rectum; a few small fluid levels present; probably an ileus rather than an obstruction'. Surgical correction on sixth day. Survived.

The remaining 12 infants (Cases 13-24) presented with signs of intestinal obstruction during the first three days of life due to either a functional ileus or to a meconium plug. Their clinical features are summarized in Table 1 and their case histories reported below.

Case 13. A girl, weighing $2 \mathrm{lb} .10 \mathrm{oz}$. (1,290 g.), was delivered by caesarian section at 33 weeks' gestation because of maternal toxaemia of pregnancy. Condition at birth was poor and for three days she was critically ill with respiratory distress and cyanotic attacks. Normal meconium was passed in small amounts from the first day. Generalized abdominal distension and small bilestained vomits were noted on the second day and continued for a further two days. Moderate jaundice also developed. From the fifth day steady progress was made and she returned home after seven weeks weighing $4 \mathrm{lb} .11 \mathrm{oz}$. $(2,124 \mathrm{~g}$.).

Case 14. This boy, weighing $2 \mathrm{lb} .14 \mathrm{oz} .(1,303 \mathrm{~g}$.$) ,$ was born by normal delivery at 33 weeks. The mother, 


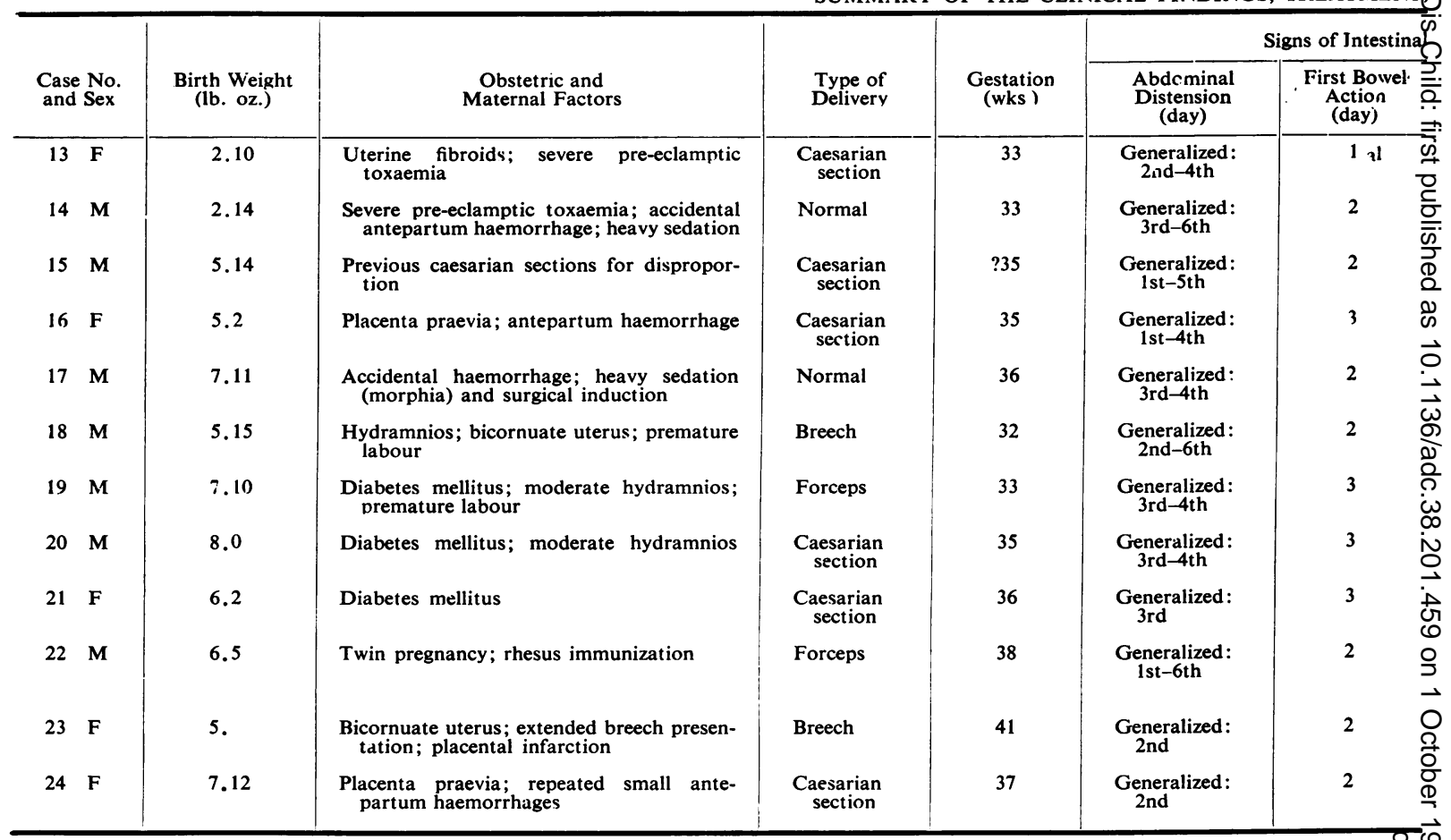

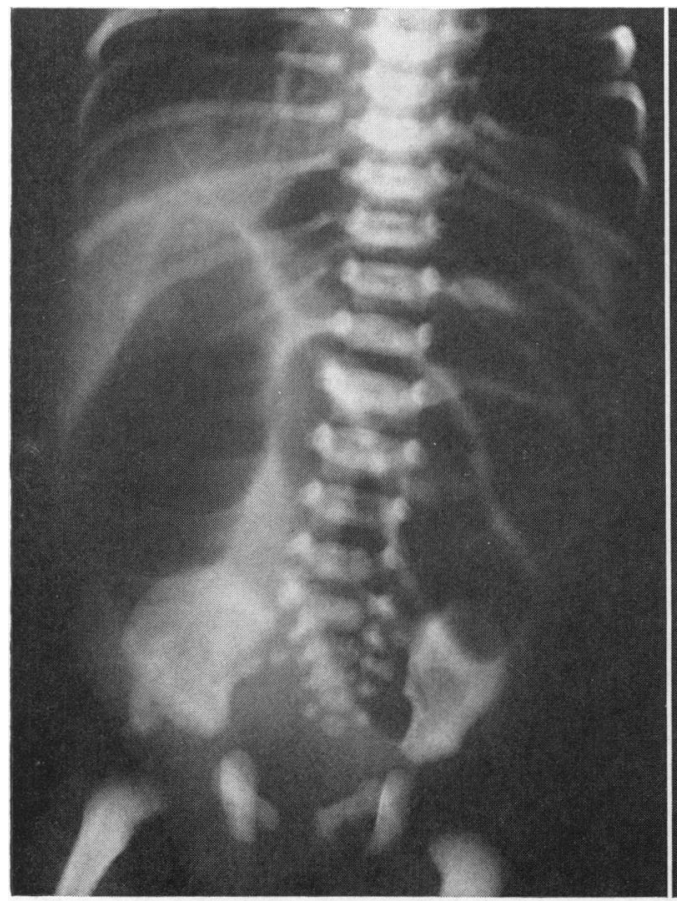

FIG. 1.-Case 11: Ileal atresia on the second day.

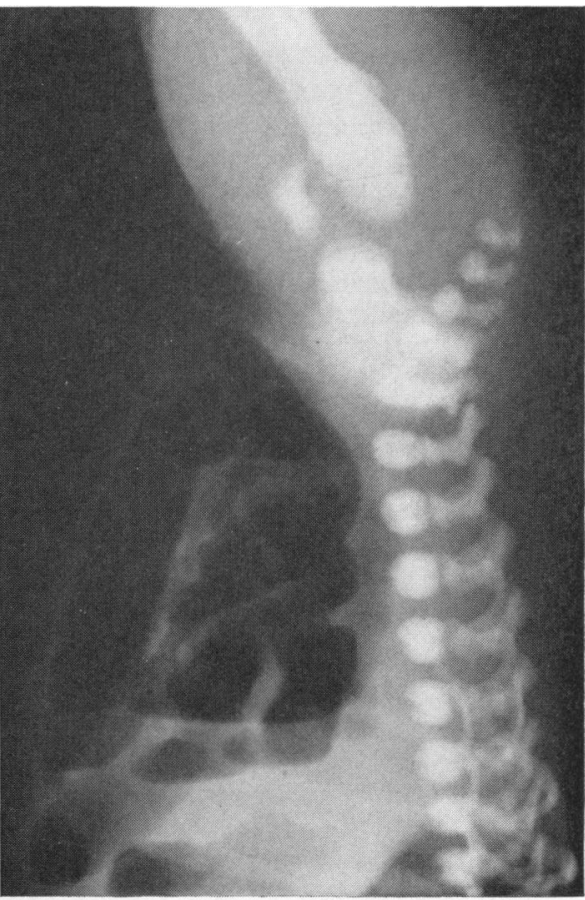

(a) Supine A-P view; (b) inverted lateral view. 


\begin{tabular}{|c|c|c|c|c|c|}
\hline \multicolumn{2}{|l|}{ Obstruction } & \multirow[b]{2}{*}{$\begin{array}{l}\text { Concomitant Clinical } \\
\text { Findings }\end{array}$} & \multirow[b]{2}{*}{ Treatment } & \multirow[b]{2}{*}{ Result } & \multirow[b]{2}{*}{ Final Diagnosis } \\
\hline $\begin{array}{l}\text { Character of } \\
\text { First Stool }\end{array}$ & $\begin{array}{l}\text { Vomiting } \\
\text { (day) }\end{array}$ & & & & \\
\hline Meconium & 2nd, 3rd, 5th & $\begin{array}{l}\text { Poor condition at birth; severe respiratory distress; } \\
\text { cyanotic attacks; moderate jaundice }\end{array}$ & Medical & Alive & Functional ileus \\
\hline Meconium & $\overrightarrow{3 r d}(B)$ & $\begin{array}{l}\text { Poor condition at birth; severe respiratory distress; } \\
\text { cyanotic attacks }\end{array}$ & Medical & Alive & Functional ileus \\
\hline Meconium & 2nd-3rd & Severe respiratory distress; moderate jaundice & Medical & Alive & Functional ileus \\
\hline Meconium & 2nd & Poor condition at birth; severe respiratory distress & Medical & Alive & Functional ileus \\
\hline Meconium & - & $\begin{array}{l}\text { Poor condition at birth; respiratory distress; cyanotic } \\
\text { attacks }\end{array}$ & Medical & Alive & Functional ileus \\
\hline Meconium & $\overrightarrow{2 n d-4 t h}$ & $\begin{array}{l}\text { Poor condition at birth; severe respiratory distress; } \\
\text { severe jaundice }\end{array}$ & Medical & Alive & Functional ileus \\
\hline $\begin{array}{l}\text { Meconium } \\
\text { plug }\end{array}$ & 一 & $\begin{array}{l}\text { Cushinoid appearance; severe respiratory distress; } \\
\text { severe jaundice }\end{array}$ & Medical & Alive & $\begin{array}{l}\text { Functional ileus; } \\
\text { meconium plug }\end{array}$ \\
\hline $\begin{array}{l}\text { Meconium } \\
\text { plug }\end{array}$ & $\overline{3 r d}$ & Cushinoid appearance; respiratory distress & Medical & Alive & $\begin{array}{l}\text { Functional ileus; } \\
\text { meconium plug }\end{array}$ \\
\hline $\begin{array}{l}\text { Meconium } \\
\text { plug }\end{array}$ & $\overrightarrow{3 r d}(B)$ & Respiratory dist ress & Medical & Alive & $\begin{array}{l}\text { Functional ileus; } \\
\text { meconium plug }\end{array}$ \\
\hline Meconium & 2nd-6th & $\begin{array}{l}\text { First twin; severe } \mathrm{Rh} \text { haemolytic disease (cord } \mathrm{Hb} \\
35 \% \text { ); exchange transfusion; inspissated bile } \\
\text { syndrome; haemorrhagic disease }\end{array}$ & Medical & Alive & Functional ileus \\
\hline Meconium & 2nd & Poor condition at birth; cerebral irritability & Medical & Alive & Functional ileus \\
\hline Meconium & $2 \mathrm{nd}(\mathrm{B})$ & $\begin{array}{l}\text { Poor condition at birth; shock due to foetal } \\
\text { exsanguination (cord } \mathrm{Hb} 55 \% \text { ); transfusion at } \\
\text { birth }\end{array}$ & $\begin{array}{l}\text { Operation } \\
\text { (2nd day) }\end{array}$ & Alive & $\begin{array}{l}\text { Functional ileus: } \\
\text { ? meconium plug }\end{array}$ \\
\hline
\end{tabular}

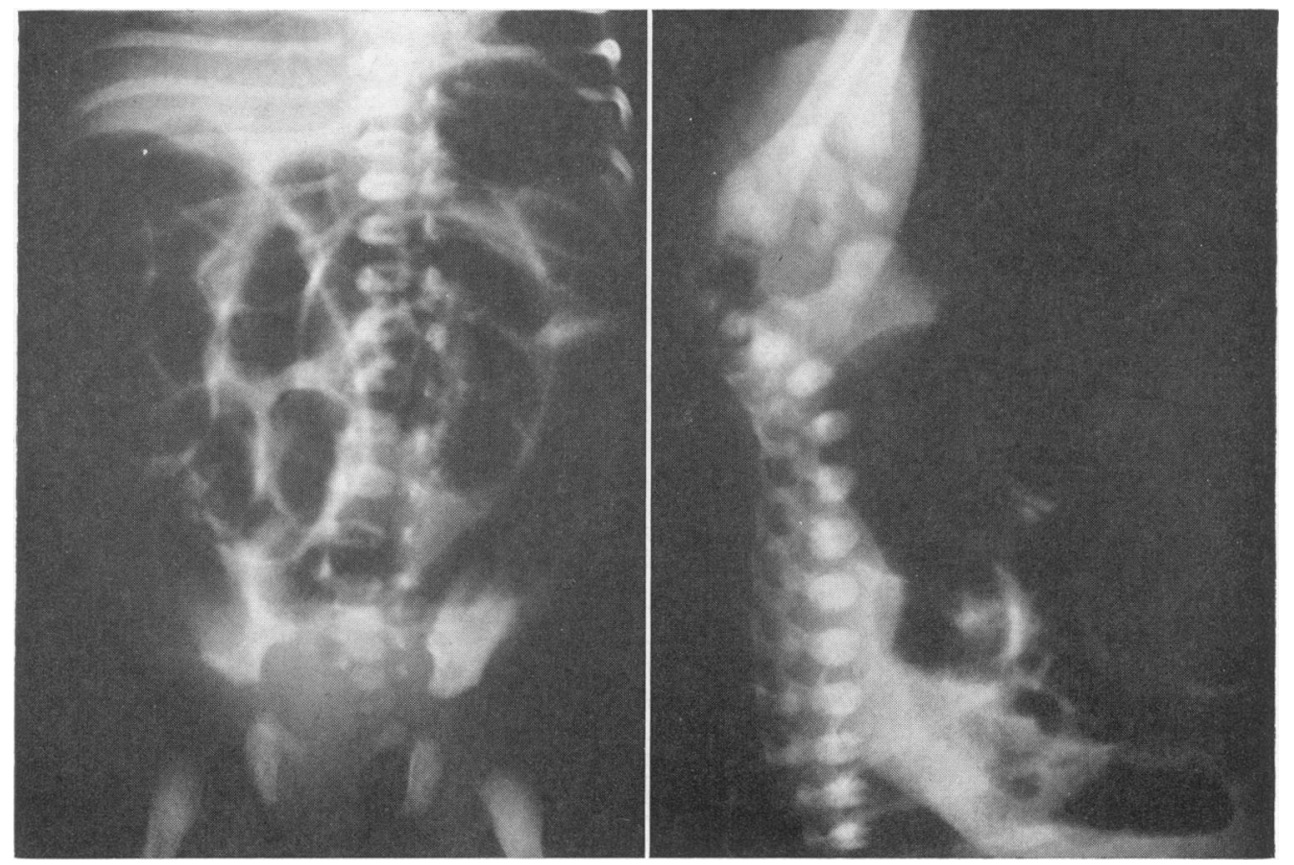

Fig. 2.-Case 12. Ileal stenosis near the ileo-colic valve of recent origin on the 3rd day. (a) Supine A-P view; (b) inverted lateral view. 
aged 36, who had had two abortions previously, had been admitted following an accidental haemorrhage complicating severe toxaemia. She was heavily sedated and when she went into labour shortly afterwards, the foetal heart could not be heard. However, the baby was born alive, though in very poor condition and rapidly developed respiratory distress syndrome. For the first two days he was very ill-limp, lethargic, oedematous and having cyanotic attacks-but thereafter showed improvement, and feeding was commenced. On the third day, abdominal distension was noted and he vomited bright green material. Only two small meconium stools had been passed since birth, the first on the second day. The abdomen was silent. He was treated conservatively over the next four days. There was no further vomiting and one meconium stool was passed each day. At the end of the first week, visible bowel pattern was seen, more stools were passed and the distension subsided. When 8 weeks old, he was discharged weighing $5 \mathrm{lb}$. (2,267 g.).

Case 15. This boy was delivered by elective caesarian section at '39' weeks' gestation because of two previous sections for disproportion. However, he weighed $5 \mathrm{lb} .14 \mathrm{oz}$. (2,663 g.) and his appearance, behaviour and bone age corresponded to 35 weeks' gestation. In retrospect, there was doubt about the accuracy of the mother's 'dates'. The respiratory distress syndrome appeared soon after birth and for two days the baby was very ill. Abdominal distension was noted late on the first day and became progressively more marked until the fourth and fifth days. The first small meconium stool was passed on the second day and thereafter they were passed daily till the seventh day when a changing stool was noted. There were four bile-stained vomits on the third day and two on the fourth. Feeding had been commenced on the second day and was never discontinued though restricted to very small quantities for the first five days. A radiograph on the fourth day showed moderate distension of the whole intestine down to the anus but no other evidence of obstruction. Moderately severe 'physiological' jaundice was also noted during the first few days. Steady improvement started on the fifth day and continued. He was discharged home on the fifteenth day weighing $5 \mathrm{lb} .5 \mathrm{oz}$. (2,408 g.).

Case 16. This girl weighing $5 \mathrm{lb} .2 \mathrm{oz}$. $(2,322 \mathrm{~g}$.) was delivered by caesarian section at 35 weeks' gestation because of placenta praevia. Her condition at birth was poor and she became extremely ill with respiratory distress syndrome. Abdominal distension was noted on the first day and lasted for four days. Small vomits, some of them bile-stained, commenced on the second day. Meconium was first passed on the fourth day. Improvement followed soon afterwards and she returned home weighing $5 \mathrm{lb} .1 \mathrm{oz}$. (2,295 g.) on the seventeenth day.

Case 17. The mother was heavily sedated with morphia and labour was induced following an accidental antepartum haemorrhage at 36 weeks' gestation. Normal delivery of a boy weighing $7 \mathrm{lb} .11 \mathrm{oz}$. $(3,486 \mathrm{~g}$.) in poor condition followed. During the next two days he had cyanotic attacks attributed to respiratory distress syndrome. Abdominal distension was noted on the third day and a radiograph on the fourth day showed moderate gaseous distension of the intestine down to the rectum. A trace of meconium was passed on the second and third days but was not passed in any quantity until the fourth day. Thereafter the distension subsided and progress was normal.

Case 18. A boy weighing $5 \mathrm{lb} .15 \mathrm{oz}$. $(2,692 \mathrm{~g}$.) was born by breech extraction at 32 weeks' gestation. The mother had been admitted in labour following premature rupture of the membranes. Because considerable hydramnios had been noted a stomach tube was passed soon after birth to exclude oesophageal atresia. The baby was difficult to resuscitate and soon exhibited signs of respiratory distress syndrome with which condition he remained critically ill for three days. He also became severely jaundiced. Feeding was commenced on the second day and at that time abdominal distension was first noted. This continued until the seventh day. Small bright green vomits started on the second day and continued for three days. The first trace of meconium was passed on the second day and was thereafter only passed in very small quantities till the sixth day. On the fourth day, radiographs of the abdomen showed moderate distension of the whole intestine down to the anus (Fig. 3). From the fifth day improvement commenced and was maintained. He was discharged at 3 weeks weighing $5 \mathrm{lb} .15 \mathrm{oz}$. (2,692 g.).

Case 19. The mother, a diabetic, exhibited moderate hydramnios, and labour commenced spontaneously at 33 weeks' gestation. The baby, a boy weighing $7 \mathrm{lb} .10 \mathrm{oz} .(3,458 \mathrm{~g}$.$) , was delivered by forceps and had$ a typical cushinoid appearance. He was extremely ill with respiratory distress syndrome for the first three days. No meconium was passed during the first two days and examination at 48 hours revealed an empty rectum. On the third day the abdomen was very distended. Bowel sounds could now be heard. The same day two small meconium plugs were passed and normal meconium followed. The abdominal distension had subsided by the fifth day. No vomiting was recorded. He returned home on the 26th day weighing $7 \mathrm{lb} .11 \mathrm{oz}$. $(3,486 \mathrm{~g}$.).

Case 20. This boy, weighing $8 \mathrm{lb}$. $(3,629$ g.), was delivered by elective caesarian section at 36 weeks because of longstanding severe maternal diabetes mellitus. Moderate hydramnios had been noted since the 27th week. The baby had a cushinoid appearance. He was slow to breathe and soon showed the typical signs of severe respiratory distress syndrome. A moderate degree of jaundice also developed. Marked abdominal distension and ladder patterning were visible on the third day (Fig. 4) and he vomited twice (no bile). Rectal examination on the third day produced a meconium plug and four more meconium stools followed shortly afterwards. The next day the abdominal distension was less marked and a further 13 meconium stools were passed. Thereafter progress was normal and he was 


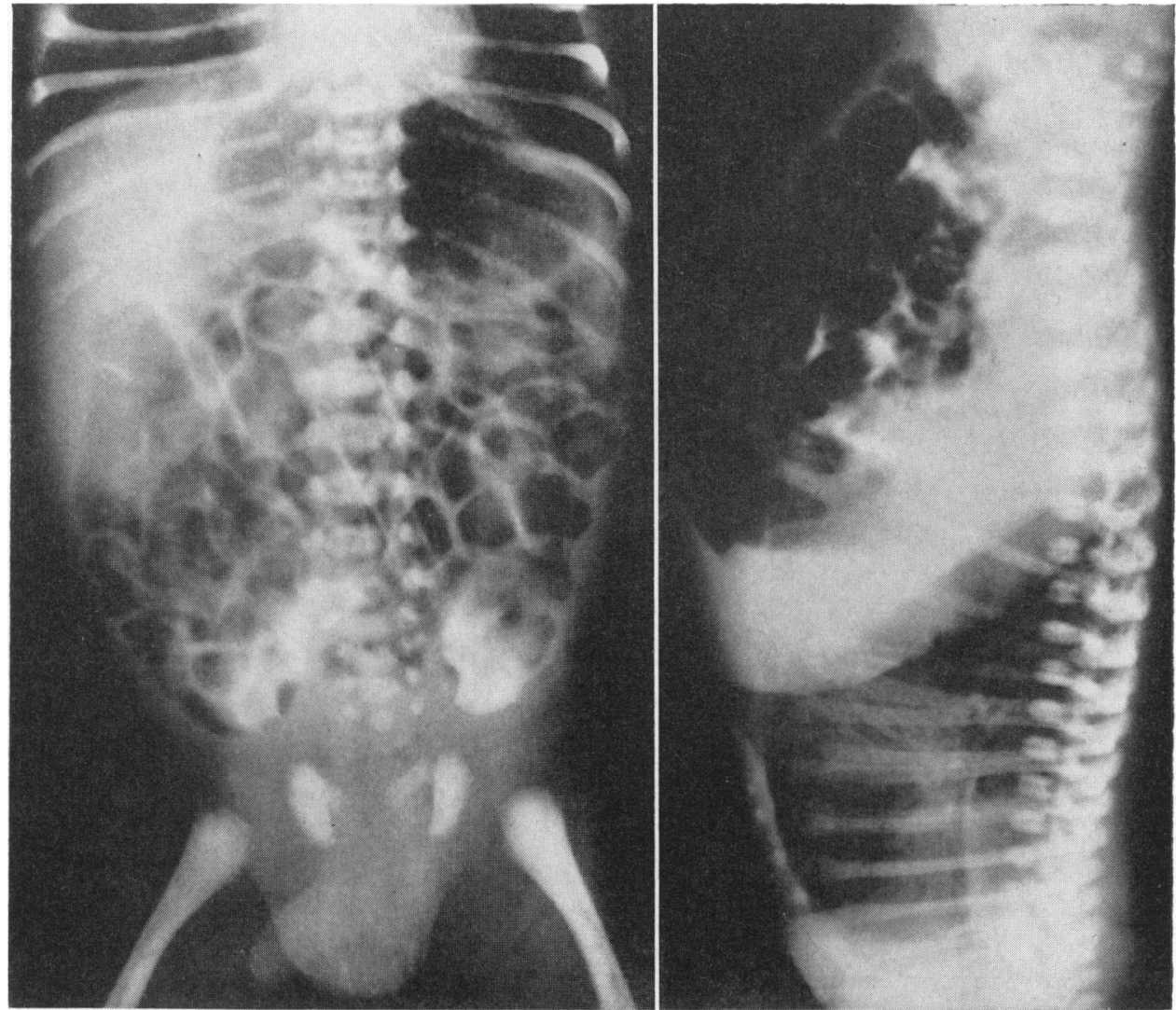

Fig. 3.-Case 18. Functional ileus associated with respiratory distress syndrome on the fourth day. (a) Supine A-P view; (b) inverted lateral view.

discharged home on the eleventh day weighing $7 \mathrm{lb} .6 \mathrm{oz}$. (3,345 g.).

Case 21. A girl, weighing $6 \mathrm{lb} .2 \mathrm{oz}$. (2,778 g.) was delivered by caesarian section because of maternal diabetes. She exhibited a mild degree of respiratory distress syndrome. No meconium was passed during the first two days. On the third day there was marked abdominal distension and two small bile-stained vomits. Later on the same day a meconium plug, followed by a large amount of meconium, was passed and the abdominal distension then subsided. She returned home on the seventeenth day weighing $6 \mathrm{lb}$. $2 \mathrm{oz}$. (2,778 g.).

Case 22. A boy, the first of twins and weighing $6 \mathrm{lb} .5 \mathrm{oz}$. (2,863 g.), was delivered at 38 weeks' gestation with the aid of forceps. At birth he was critically ill due to severe $\mathrm{Rh}$ incompatibility (cord $\mathrm{Hb} 35 \%$ ), heart failure and respiratory distress. He also exhibited haemorrhagic disease of the newborn and the inspissated bile syndrome. An exchange transfusion and digitalization were required. Abdominal distension, which was present from birth, became more marked during the first three days and only started to subside at the end of the first week. Small meconium stools were passed from the second day. Bile-stained vomiting commenced on the second day and persisted for six days. A radiograph on the fifth day showed only generalized gaseous distension of the intestine. For eight days he required

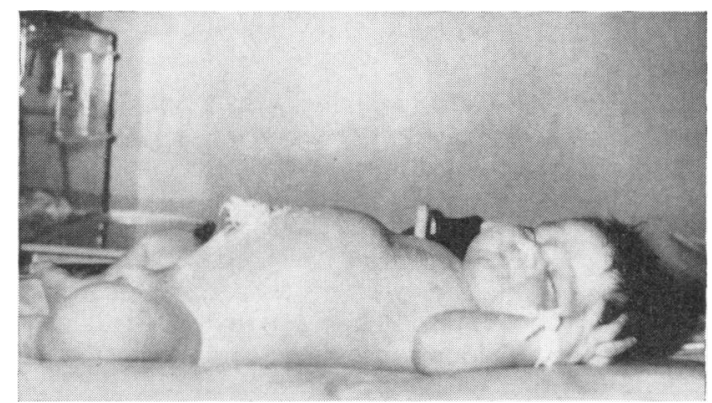

Fig. 4.-Case 20. Abdominal distension due to functional ileus and meconium plug in infant of a woman with diabetes (third day). 


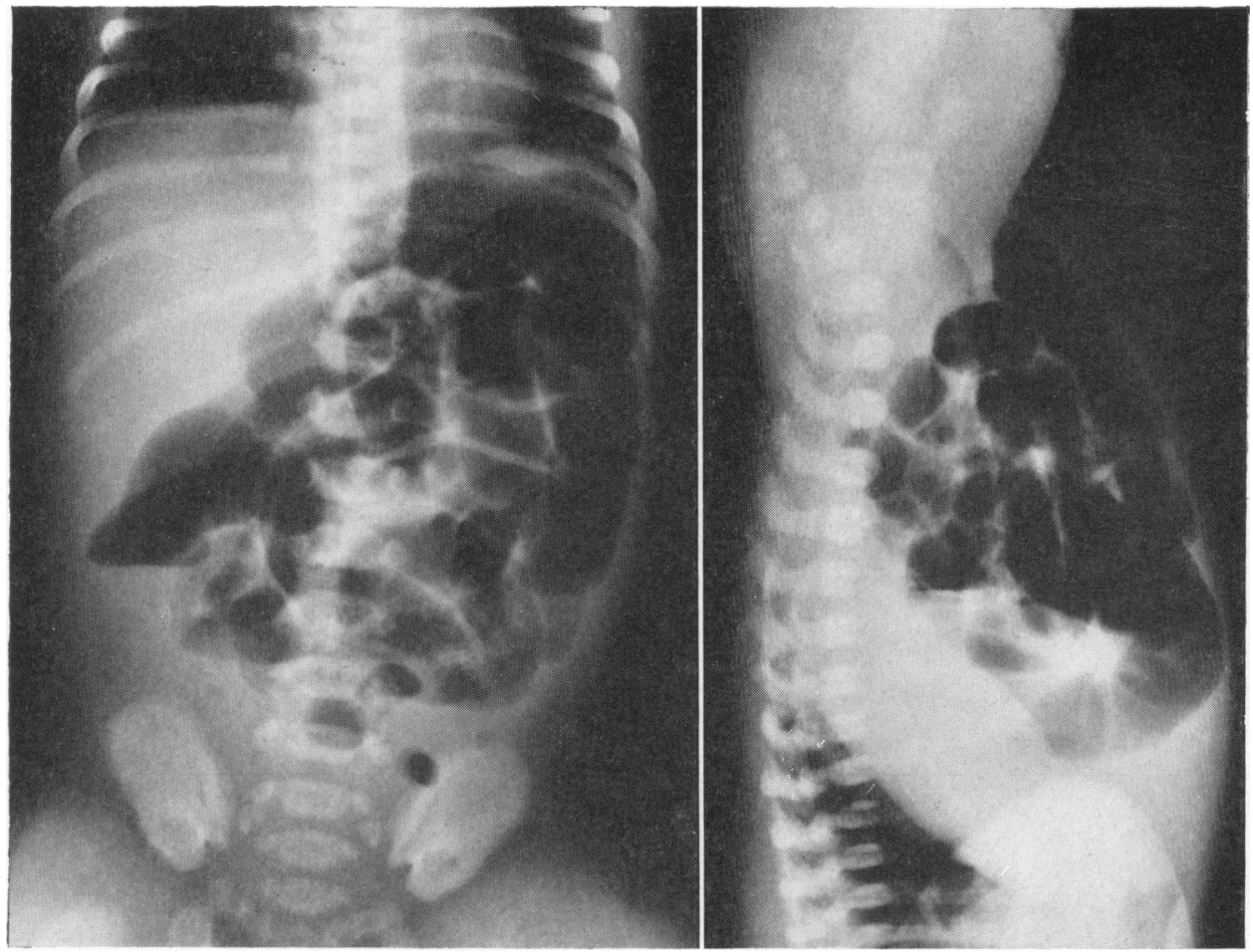

Fig. 5.-Case 24: Functional ileus and probable meconium plug on second day. (a) Erect A-P view; (b) inverted lateral view.

gastric aspiration and parenteral fluids. Thereafter his condition improved.

Case 23. A girl weighing $5 \mathrm{lb} .7 \mathrm{oz}$. $(2,465$ g.) was delivered by the breech at 41 weeks' gestation. The mother had a bicornuate uterus and the placenta was very infarcted. After delivery, the baby exhibited a moderate degree of cerebral irritability for which she received phenobarbitone. Abdominal distension and vomiting were noted late on the second day. The first small meconium stool was then passed following a rectal examination. On the third day more meconium was passed, the distension subsided and the vomiting stopped. She returned home on the fifteenth day weighing $5 \mathrm{lb} .4 \mathrm{oz}$. (2,380 g.).

Case 24. This girl, weighing 7 lb. $12 \mathrm{oz}$. (3,515 g.), was delivered by elective caesarian section at 37 weeks following repeated small antepartum haemorrhages during the previous 10 weeks, associated with a low-lying placenta. The baby was very pale at birth ( $\mathrm{Hb} 55 \%$ ) and in a state of acute oligaemic shock. A diagnosis of foetal exsanguination was made and an immediate transfusion of $100 \mathrm{ml}$. O Rh negative blood was given. A dramatic clinical improvement followed. On the second day she was a little irritable but otherwise in reasonable condition. A feed was offered but was returned with considerable green bile staining. The abdomen was distended and silent. No meconium had been passed and none was present on rectal examination. In spite of gastric aspiration there were two more bilestained vomits that day and she was transferred to the Children's Hospital. There, a radiograph taken at 36 hours of age, was reported as showing 'moderate distension with fluid levels in the small bowel and some meconium mottling; air filling of the colon is uncertain but there is none in the rectum or lower colon' (Fig. 5). A laparotomy was performed (Mr. A. Gourevitch) and the terminal ileum and ascending colon was found to be grossly distended with meconium to such a degree that the serosa had split in one place. No cause for the obstruction was apparent but, because Hirschsprung's disease was suspected, a colostomy was performed. However, later biopsy reports were normal and the colostomy was finally closed. After a number of complications, she was discharged home at the age of 3 months weighing $9 \mathrm{lb} .5 \mathrm{oz}$. $(4,224 \mathrm{~g}$.) and with a normal bowel action. Thereafter her progress has been uneventful.

\section{Discussion}

The incidence of perinatal intestinal obstruction in this series was 5 per 1,000 , functional obstruction and anatomical abnormality contributing equally to the total. However, functional abnormality was 
responsible for four-fifths of the cases presenting as diagnostic problems. We estimate that these figures may be at least three times as great as those for the country as a whole owing to the selection of cases for delivery in this hospital, the significance of which must be apparent from the case summaries.

Aetiology. The aetiology of the anatomical causes of intestinal obstruction has been well reviewed (Ladd, 1933; Nixon, 1955; Louw, 1959; Singleton, Rosenberg and Samper, 1961) and will not be discussed further.

The concept of functional intestinal obstruction was introduced in 1948 by Zuelzer and Wilson. Their cases were due to Hirschsprung's disease and the importance of this condition as a cause of neonatal obstruction has since been emphasized (Swenson and Bill, 1948; Bodian, Stephens and Ward, 1949; Ehrenpreis, 1955). A number of other functional causes have now been described, either due to abnormal bowel contents or to altered peristalsis. Among the former are meconium ileus due to mucoviscidosis (Farber, 1944; Andersen, 1945) and meconium and faecal plugs (Rack and Crouch, 1952; Clatworthy, Howard and Lloyd, 1956; Emery, 1957; Zachary, 1957), while among the latter are cases of transient ileus due to the maternal administration of ganglion blocking agents (Morris, 1953; Hallum and Hatchuel, 1954), due to heroin addiction (Raffensperger, Johnson and Greengard, 1961) or of unknown origin (Brescia and Tartaglione, 1949; Astley, 1956; Schaffer, 1960). Cases of congenital colonic inertia presenting as intestinal obstruction were also reported by Coekin and Gairdner (1960). These functional causes, along with others mentioned only briefly in other works (Koop, 1953; Rickham, 1955; Nelson, 1954; Corner, 1960) are summarized in Table 2.

The 12 infants who developed functional intestinal obstruction in this series were extremely ill either from birth or soon after. This was due to severe $\mathrm{Rh}$ incompatibility, intrauterine asphyxia and foetal exsanguination in three infants (Cases 22, 23, 24) and to respiratory distress syndrome in the remaining nine (Cases 13-21). The latter represent approximately $9 \%$ of the infants who developed respiratory distress syndrome and yet survived, during the period under review. All nine were of less than 37 weeks' gestation and five were delivered by caesarian section. Cerebral anoxia and oedema as well as metabolic disturbance may all occur with respiratory distress syndrome and may be responsible for the presumed ileus.

Two mothers were heavily sedated at the time of delivery (one with morphia) and this may have a bearing on the subsequent development of functional ileus. However, no ganglion blocking agents were administered antenatally in any of these cases.

Moore, Kay, Desmond and Dutton (1960) mentioned briefly that babies with 'transient distress' born to diabetic women might exhibit an ileus. In our series no less than three infants fall into this category (Cases 19-21). But babies born to diabetic women are prone to develop respiratory distress. In fact, during 1961 they composed approximately one-fifth of the infants surviving this condition at this hospital. At the same time, these three infants all failed to pass meconium until the third day, when each passed a meconium plug. No attempt will be made to assess the significance of this fact.

TABLE 2

CLASSIFICATION OF FUNCTIONAL INTESTINAL OBSTRUCTION IN THE NEWBORN

I: Abnormal bowel contents

Meconium ileus due to mucoviscidosis

Meconium plug syndrome

Dry, sticky meconium of dehydrated, premature baby

II : Abnormal peristalsis

(a) Large bowel

Aganglionic segment; Hirschsprung's disease

Faulty innervation; spina bifida

Idiopathic colonic inertia

(b) Paralytic ileus secondary to

Cerebral disturbance: cerebral oedema, anoxia or birth trauma

Metabolic disturbance: electrolyte; hormonal

Peritoneal irritation; peritonitis (chemical or infective) Mesenteric thrombosis

Retroperitoneal haemorrhage

Infection: parenteral (pneumonia) Pseudomonas enteritis

Maternal drugs: ganglion blocking agents

(c) Feeble peristalsis: hypotonic musculature of extreme prematurity

(d) Localized spasm: pylorospasm

Diagnosis. The classical triad of intestinal obstruction in the newborn-delay in the passage of meconium, abdominal distension and bile-stained vomiting - was considered to be pathognomonic of anatomical obstruction by many authors in the past. That these signs may equally accompany functional obstruction is demonstrated in this series (Table 3). In fact abdominal distension is common among newborn babies and $6 \%$ fail to pass meconium on the first day of life (Sherry and Kramer, 1955). With regard to bile-stained vomiting, our experience differed from that of Nixon (1955) in that among the 19 babies who were noted to vomit green material during this two-year period, four 
TABLE 3

\begin{tabular}{|c|c|c|c|c|c|c|c|}
\hline \multicolumn{4}{|c|}{$\begin{array}{l}\text { Type of Intestinal Obstruction } \\
\text { (presenting after birth) }\end{array}$} & $\begin{array}{c}\text { Maternal } \\
\text { Hydramnios }\end{array}$ & $\begin{array}{l}\text { Abdominal } \\
\text { Distension }\end{array}$ & $\begin{array}{l}\text { Delay in Passage of } \\
\text { Meconium Over } \\
24 \text { hours }\end{array}$ & $\begin{array}{l}\text { Bile-stained } \\
\text { Vomiting }\end{array}$ \\
\hline Anatomical abnormality & $\ldots$ & $\ldots$ & $\cdots$ & 2 out of 3 & 2 out of 3 & 2 out of 3 & 3 out of 3 \\
\hline Functional abnormality & . & $\ldots$ & $\ldots$ & 3 out of 12 & 12 out of 12 & 11 out of 12 & 8 out of 12 \\
\hline
\end{tabular}

had an anatomical obstruction, eight had a functional obstruction and the remaining seven had no other evidence suggestive of obstruction. In spite of this, the diagnosis of intestinal obstruction and the differential diagnosis between the two groups may be made with reasonable confidence in most cases with the aid of the clinical signs and investigations now to be discussed.

Maternal hydramnios is an important indication of anatomical obstruction of the alimentary tract above the level of the ileum (Scott and Wilson, 1957; DeYoung, 1958; Lloyd and Clatworthy, 1958; Jeffcoate and Scott, 1959). However, its absence does not exclude anatomical obstruction when the latter develops just before or after birth, when it is well below the level of the jejunum or is incomplete. In this series it heralded both the case of duodenal atresia and that of high ileal atresia. Hydramnios also accompanied three infants who subsequently developed a functional ileus. However, two were born to mothers with diabetes mellitus, a condition known to be associated with the presence of moderate hydramnios. It is suggested, therefore, that an unexplained history of acute hydramnios warrants an abdominal radiograph 12-24 hours after birth in order to check the passage of air down the bowel. If this practice had been followed by us, the diagnoses of Cases 10 and 11 would have been made on the first day instead of later.

Meconium accumulates in the rectum throughout the second half of pregnancy (Keith, 1933; Davis and Potter, 1946; Potter, 1961). Delayed passage, beyond 24 hours after birth, associated with an empty rectum, suggests either a longstanding anatomical obstruction or a meconium plug. However, the passage of stools does not exclude incomplete or recent intestinal obstruction. The stools themselves may be revealing. The pale mucoid terminal 'meconium plug' (Clatworthy et al., 1956) and the tenacious putty-like meconium of mucoviscidosis are each distinctive, as is also the small dry white or pale green stool formed from the debris that has collected below a longstanding anatomical obstruction.

Abdominal distension is usually generalized with the exception of duodenal obstruction where distension, if present, tends to be localized to the epigastrium, and high small intestinal obstruction where a few loops of distended gut may often be observed through the upper abdominal wall.

The vomit is nearly always bile stained because the majority of obstructions occur below the ampulla of Vater. In this series, where it followed longstanding intrauterine obstruction, it was thick and dark green or brown; vomiting started soon after birth and was copious. In contrast, the bilestained vomit of babies without intestinal obstruction or with functional ileus was light green and thin; vomiting started somewhat later and was smaller in amount. In passing, it was interesting to note that in Case 11, with ileal atresia, the liquor amnii was observed to be meconium stained before birth. This must have been due to intrauterine vomiting as the stools were very pale green. In this context, Desmond, Moore, Lindley and Brown (1957) also noted green liquor amnii with six babies who had high intestinal obstruction.

Radiological examination, though it may fail to differentiate between the meconium plug, meconium ileus and Hirschsprung's disease (see Fig. 5), is a most useful aid to diagnosis (Wasch and Marck, 1948; Ehrenpreis, 1955; Astley, 1956). Besides the usual supine or erect radiograph, a lateral inverted film should be taken as this enables gas to be traced down into the rectum of the normal subject. The typical appearance accompanying functional ileus is of moderate gaseous distension of the whole intestine down to the anus without evidence of obstruction (Fig. 3). However, this appearance was to some extent mimicked by the incomplete anatomical obstruction of Case 12 (Fig. 2).

Prognosis and Treatment. The ileus of the infants with functional obstruction always appeared within the first three days of life and started to resolve by the end of the first week, if not before. Perhaps this was due to the self-limiting nature of the associated conditions, in particular the respiratory distress syndrome.

Most of these infants were so ill that a laparotomy 
would probably have been fatal, as well as unnecessary. Our management was conservative. Gastric aspiration and parenteral fluids were occasionally required. Associated respiratory distress, however, was energetically treated with oxygen, digoxin and antibiotics, and all these infants survived.

\section{Summary}

Twenty-four babies presented with intestinal obstruction at birth or in the first week of life among 4,754 consecutive births at a maternity hospital. Anatomical and functional abnormalities contributed equally to the total.

The aetiological classification of functional intestinal obstruction is presented. The relation between transient functional ileus and respiratory distress syndrome is discussed.

The differentiation between anatomical and functional types of obstruction is discussed and its importance in relation to management is stressed.

I wish to thank Dr. B. S. B. Wood both for his advice and encouragement and for permitting me to publish his cases. Dr. R. Astley kindly read through the manuscript and commented on the radiographs. I am also grateful to the obstetricians, radiologists, surgeons and nurses who assisted in the care of these infants, to Miss V. Macdonald for her invaluable secretarial assistance and to Mr. W. J. Hurt for preparing the photographs.

The author was supported by a grant from the United Birmingham Hospitals endowment fund.

Andersen, I). H. (1945). Celiac syndrome. II. Fecal excretion in congenital pancreatic deficiency at various ages and with various diets, with discussion of the optimal diet. Amer. J. Dis. Child., 69, 221 .

Astley, R. (1956). Radiology of the Alimentary Tract in Infancy. Arnold, London.

Bodian, M., Stephens, F. D. and Ward, B. C. H. (1949). Hirschsprung's disease and idiopathic megacolon. Lancet, 1, 6.

Brescia, M. A. and Tartaglione, E. F. (1949). Functional intestinal obstruction in an infant. Arch. Pediat., 66, 387. Clatworthy, H. W., Jr., Howard, W. H. R. and Lloyd. J. (1956).
The meconium plug syndrome. Surgery, 39, 131.

Coekin, M. and Gairdner, D. (1960). Faecal incontinence in children: The physical factor. Brit. med.J., 2, 1175

Corner, B. (1960). Prematurity. Cassell, London.

Davis, M. E. and Potter, E. L. (1946). Intrauterine respiration of the human fetus. J. Amer. med. Ass., 131, 1194.
Desmond, M. M., Moore, J., Lindley, J. E. and Brown, C. A. (1957). Meconium staining of the amniotic fluid. Obstet. and Gynec., 9,91.

DeYoung, V. R. (1958). Hydramnios as a signal to the physician responsible for newborn infants. J. Pediat., 53, 277.

Ehrenpreis, Th. (1955). Hirschsprung's disease in the neonatal period. Arch. Dis. Childh., 30, 8.

Emery, J. L. (1957). Abnormalities in meconium of the foetus and newborn. ibid., 32, 17.

Farber, S. (1944). The relation of pancreatic achylia to meconium ileus. J. Pediat., 24, 387.

Hallum, J. L. and Hatchuel, W. L. F. (1954). Congenital paralytic ileus in a premature baby as a complication of hexamethonium bromide therapy for toxaemia of pregnancy. Arch. Dis. Childh., 29, 354 .

Jeffcoate, T. N. A. and Scott, J. S. (1959). Polyhydramnios and oligohydramnios. Canad. med. Ass. J., 80, 77.

Keith, A. (1933). Human Embryology and Morphology, 5th ed Arnold, London.

Koop, C. E. (1953). Intestinal obstruction in the neonatal period. Advanc. Pediat., 6, 63.

Ladd, W. E. (1933). Congenital obstruction of the small intestine. J. Amer. med. Ass., $101,1453$.

Lloyd, J. R. and Clatworthy, H. W., Jr. (1958). Hydramnios as an aid to the early diagnosis of congenital obstruction of the alimentary tract: A study of the maternal and fetal factors. Pediatrics, 21, 903 .

Louw, J. H. (1959). Congenital intestinal atresia and stenosis in the newborn: observations on its pathogenesis and treatment. Ann. roy. Coll. Surg. Engl., 25, No. 4 (Nov.), 209.

Moore, C. E., Kay, J. L., Desmond, M. M. and Dutton, R. V. (1960), Transitional distress in infants of diabetic mothers. J. Pediat., 57, 824 .

Morris, N. (1953). Hexamethonium compounds in the treatment of pre-eclampsia and essential hypertension during pregnancy. Lancet, 1, 322.

Nelson, W. E. (1954). Textbook of Pediatrics, 6th ed. Saunders, Philadelphia

Nixon, H. H. (1955). Intestinal obstruction in the newborn. Arch. Dis. Childh., 30, 13.

Potter, E. L. (1961). Pathology of the Fetus and Infant, 2nd ed.

Year Book Publishers, Chicago.
Rack, F. J. and Crouch, W. L. (1952). Functional intestinal obstruction in the premature newborn infant. J. Pediat., 40, 579.

Raffensperger, J., Johnson, F. R. and Greengard, J. (1961). Nonmechanical conditions simulating obstructive lesions of the intestinal tract in the newborn infant. Surgery, 49, 696.

Rickham, P. P. (1955). Peritonitis in the neonatal period. Arch. Dis. Childh. $30,23$.

Schaffer, A. J. (1960). Diseases of the Newborn. Saunders, Philadelphia.

Scott, J. S. and Wilson, J. K. (1957). Hydramnios as an early sign of oesophageal atresia Lancet, 2, 569.

Sherry, S. N. and Kramer, I. (1955). The time of passage of the first stool and first urine by the newborn infant. J. Pediat., 46, 158.

Singleton, E. B., Rosenberg, H. M. and Samper, L. (1961). Radiologic considerations of the perinatal distress syndrome. Radiology, 76, 200.

Swenson, O. and Bill, A. H. (1948). Resection of rectum and rectosigmoid with preservation of the sphincter for benign spastic lesions producing megacolon. Surgery, 24, 212.

Wasch, M. G. and Marck, A. (1948). The radiographic appearance of the gastrointestinal tract during the first day of life. J. Pediat., 32, 479.

Zachary, R. B. (1957). Meconium and faecal plugs in the newborn. Arch. Dis. Childh., 32, 22.

Zuelzer, W. W. and Wilson, J. L. (1948). Functional intestinal obstruction on a congenital neurogenic basis in infancy. Amer. J. Dis. Child., 75, 40. 